\title{
Moral Agency in Mammalia
}

\author{
Dr. Mark D. Reid, Ph.D. \\ Philosophy Department \\ Wilkes University \\ thoughtmark@gmail.com
}

\begin{abstract}
About the extent of moral agency in the animal kingdom, one view is that only humans are moral agents. Holding a different view, I argue that moral agency depends on the capacity for other-regard and the capacity to be attuned to significance-such that things matter to one. I derive a criterion where a creature is a moral agent if she performs an action that promotes others' significant interests and brings great costs to herself where she is aware of these significant interests and imposed costs. Failure to confirm that she has this awareness is a weakness of examples of moral agency in animals that writers provide, since she may be unaware of the significance of what she is doing. Since species of non-ape Primates and aquatic mammals satisfy the evidential criterion, moral agency is likely prevalent throughout much of Mammalia. I consider possible objections from Kant, Singer, and Korsgaard.
\end{abstract}

\section{Introduction}

Various hypotheses are possible about a moral agent's psychological capacities. The assumption seems reasonable that the capacity to have thoughts about the welfare of others is, though not the whole story, central to moral agency. To assist us in figuring out what sort of higher-order intentionality, if any, is necessary and/or sufficient for moral agency, it helps, first, to distinguish a higherorder thought from a higher-order intentional state. By a "higherorder thought," I mean a thought that takes a thought as its object. By a "higher-order intentional state," I mean a thought that takes an intentional state as its object.

Reflective and empirical evidence suggests that higher-order thought is unnecessary and insufficient for moral agency (with higher -order intentionality being necessary but not sufficient). Reflectively speaking, an agent may be able to have thoughts about the mental states of others, which may lack significance for the agent. Although psychopaths are proficient in higher-order thought, theory of mind, 
and means-ends reasoning, experts with direct experience with psychopaths conclude that psychopaths are amoral (Cleckley, 1976; Hare, 1993). ${ }^{1}$ Moreover, normal people explain the wrongness of a moral violation by appeal to the victim's distress, and they distinguish moral violations from conventional violations as being more serious, impermissible, and independent of authority (Blair 1995); even children as young as thirty-four months of age distinguish moral from conventional violations (Smetana 1993). In contrast, psychopaths see a moral violation such as forgery in the same way that they see a conventional violation such as poor etiquette. ${ }^{2}$ Psychopaths not only fail to distinguish moral violations from conventional violations, they explain them similarly, and they fail to appeal to the victim's distress (Blair 1995). The psychopath's higher-order thought and amorality strongly suggest that higherorder thought is insufficient for moral agency.

Reflective evidence suggests that higher-order thought is unnecessary for moral agency, since a moral agent could care about others and act to reduce their discomfort by representing and acting on the emotional or physiological states of others. Assuming that we sometimes attribute emotional or physiological states without attributing thoughts to a newborn, we may represent and act similarly when we, for example, alleviate its pain. Autism is a condition characterized by selective impairments in higher-order thought and theory of mind (Baron-Cohen 1995). Despite these impairments, however, children with autism not only distinguish moral from conventional violations (Rogers at al. 2008), they are "as likely as controls [age-matched children without autism] to judge culpability on the basis of motive, and to judge injury to persons as more culpable than damage to property" (Grant et al. p. 317). Although these findings on psychopathy and autism suggest that higher-order thought is unnecessary and insufficient for moral agency, the capacity to have thoughts about the welfare of others may nevertheless be central to moral agency. 
After making a general case for the existence of the mammalian mind, I propose criteria for being a moral agent and show that members of nonhuman species of mammals satisfy them.

\section{Mammals' Minds}

When humans engage in complex behaviors that do not require language, such as climbing a tree, hiking new mountain terrain, or lovemaking, the fact that we are also engaging in thought is beyond dispute. Since nonhuman mammals engage in similar activities in similar ways, by a principle of parity, they are also engaging in thought. If they engage in thought, they have minds.

In one example of a study of many thousands in the expansive literature that documents the complexity of mammals' minds, researchers made audio recordings of elephants for playback to familiar and unfamiliar elephants (McComb 2003). When elephants heard the voice of a family member while the family member was absent, they vocalized back and pursued the source of the sound. If the family member was already present, they showed little response. When they heard a strange elephant, they quickly assumed a defensive formation and retreated from the source of the sound. These studies suggest that elephants are capable of auditorily discriminating elephants as individuals. If they do that, they must have minds with a social awareness of the individual identities of other elephants. Marc Hauser reports that, upon discovering food, rhesus monkeys who keep the discovery to themselves receive aggression from other monkeys. Moreover, "Individuals were able to detect the discoverer amidst a group of individuals with food and punish just that discoverer and not additional "walk-ons,"” which shows that the behavior was intentional, rather than generalized anger (p. 12139). These findings suggest that rhesus monkeys may also have a social awareness of other monkeys as individuals, and that they have a desire to punish hoarding behavior if not also enforcing some sense of what a monkey should not do. According to dolphin trainer Karen Pryor (2001), "Dolphins imitate each other with or without training" and perform "repertoires that they learned 
only by watching through a gate as the other animal performed." She believes that "the capacity [of imitation] already exists in many species, and needs only the right environmental cues to make it apparent” (p. 352). Studies on mirror self-recognition behavior report successful mirror self-recognition in one elephant, most chimpanzees and bonobos, some gorillas and orangutans, two dolphins, and several killer whales. ${ }^{3}$ Evidence suggests that some levels of self-recognition are even present in the cotton-top tamarin, a New World Monkey. ${ }^{4}$

Studies of baboons report capacities to rotate objects mentally (Vauclair et al., 1993). Based on testing and between-species comparisons of the results, one gorilla has a metaphorical capacity of the average seven-year-old human child. Beginning in infancy, this gorilla was taught to use sign language, and she has used thousands of signs at least once. Upon first seeing a cigarette lighter, she spontaneously signed "bottle match," when asked what she can think of that is hard, she signed "rock and work," and when asked what an insult is, she signed "think devil dirty" (cited in DeGrazia, p. 196-7).

Another reason for believing that nonhuman mammals have minds is the similarity in the findings of human and animal neuropsychology. For instance, Klüver-Bucy syndrome is a condition that neurosurgeons created in rhesus monkeys in the 1930 s by the unconscionable removal of the monkeys' temporal lobes. Although these monkeys had apparently normal vision, they could not see the emotional significance of events or objects in the environment. They would try, for example, to eat rats or rocks or to copulate with members of other species (Bourtchouladze 2004, p. 82). Doctors diagnosed humans with Klüver-Bucy syndrome first in the 1950s, also from bilateral lesions to the temporal lobes. The general pattern of symptoms was similar to that seen in the rhesus monkeys. These findings suggest that, with intact temporal lobes, humans and rhesus monkeys normally discriminate items in their environment according to differing levels of emotional significance, in which case rhesus 
monkeys have minds with capacities to represent objects and events with emotional significance.

An additional reason for believing that nonhumans have minds are the commitments implied by the claims made by researchers, such as Donald Griffin, Jane Goodall, and Marc Hauser, who study and write about animal behavior. Making sense of these researchers' behavior and writings also requires positing animal mental attributes. The main reason to believe that nonhuman mammals have minds is the fact that their behavior is intelligent and productive and that we need to posit a mind-a system of mental representations and processes-to explain the data of all the studies.

In light of the fact that mammals have minds in varying levels of complexity, it is clear that many complex mental capacities exist outside the human species. These capacities include complex social awareness, self-awareness, rudimentary language, metaphorical capacities, and the capacity to represent emotional significance.

\section{Descriptive Criteria of Moral Agency}

An important assumption that I make is that morality is essentially a domain of significant things that matter. If this is correct, then a moral agent is a being for whom things matter. In other words, psychological capacities attune her to significance. One capacity that is necessary for moral agency is therefore an attunement to significance capacity-the capacity such that things matter to the agent. ${ }^{5}$ In distinguishing a moral from a nonmoral point of view, philosophers widely recognize an outlook that is beyond self-interest to be crucially necessary. Another necessary capacity is therefore the capacity to represent the welfare of others, which arguably mostly consists in emotional states, such as psychological distress; in other words, the agent must have capacity for other-regarding higher-order intentionality. 
If morality involves care and concern for others, then significance in others must motivate the agent's action, and these two capacities therefore suggest:

The descriptive constitutive criterion: The agent performs an action and is motivated to perform it because she believes its performance supports the significant interests of others. ${ }^{6,7}$

This criterion is constitutive, as opposed to evidential, and with important qualifications, I offer it as a sufficient condition for being a moral agent. The qualifications are that it implies other abilities that are also necessary for moral agency. If an agent has the ability to surmise a situation, to form an idea of an action, to form the belief that performing it supports the significant interests of others, and to perform the action, then the agent will have a cognitive ability to reason and a behavioral ability to perform actions.

Any objection to the criterion will concern whether it states a sufficient condition for moral agency or whether instances can be confirmed empirically that satisfy it.

Although higher-order intentionality (like higher-order thought) is not sufficient for moral agency, it is arguably sufficient for otherregard if it includes the capacity to represent the emotional states of others. The attunement to significance capacity, other-regard, an ability to reason, and a behavioral capacity to perform actions are arguably the least necessary elements of moral agency.

An objection is that the descriptive constitutive criterion is incapable of being confirmed. This objection is valid; the descriptive constitutive criterion is difficult to confirm, since it requires knowing about a motivationin the context of the agent's belief that an action's performance supports the significant interests of others. To overcome this difficulty, we must discard claims about the agent's motivation and belief and require that her action bring great costs to herself. This emendation is imperfect, since bringing a cost to self is not necessary for an action to be a moral action. Moreover, an 
action's bringing costs to the agent and benefits to others is not sufficient to make it a moral action, since she may be unaware of the significance of what she is doing. Failure to rule out this possibility makes for a serious weakness of virtually all alleged examples of moral agency in animals.

An action that brings great costs to one and benefits to others is only a "candidate" moral action, and it might suggest that the one performing it is a moral agent. For assuranceof moral agency, however, an action must satisfy a stricter criterion:

The descriptive evidential criterion: The agent performs an action that promotes others' significant interests and brings great costs to herself, and we must confirm that she is aware that she brings great costs to herself and benefits to others. ${ }^{8,9}$

When her action satisfies the descriptive evidential criterion, we know that she is aware that she brings great costs to herself and benefits to others. When the agent is aware that her action brings great costs to herself and benefits to others, we know that the reason for benefiting others is more important to her than the reason she has to avoid bringing the costs to herself. When the costs to self are great, we know that bringing benefits to others-promoting others' significant interests-matters greatly to her. We have very good reason therefore to believe that she performed a moral action, and I will call it a "moral act with assurance".

\section{Examples}

Sperm whales: In October 1997 and 80 miles off the coast of California, marine biologists documented instances of sperm whales (Physeter macrocephalus) defending themselves from the attacks of killer whales (Orcinus orca). In the first instance, nine sperm whales defended themselves against thirty-five killer whales using a rosette with heads in the center and tails defending the perimeter. The killer whales attacked repeatedly for four hours, each attack spilling sperm whale blood and body oil into the water. Every time they succeeded 
in pulling a sperm whale from the protective rosette, one or two sperm whales left the rosette, joined the attacked sperm whale, placed themselves between the sperm whale and the attacking killer whales, and led the attacked sperm whale back into the rosette, even though, this led instantly to the killer whales viciously attacking them (p. 500). At least three and possibly all nine sperm whales received fatal wounds.

Five days later, the marine biologists sighted two groups of five sperm whales about a kilometer apart and a group of five killer whales swimming toward one of the groups. When the killer whales were about a kilometer from a sperm whale group, that sperm whale group submerged for less than a minute and signaled to sperm whales in surrounding waters using a distress call. Immediately, the five sperm whales of the other group "started traveling rapidly toward" them (p. 501). Additional sperm whales heard the distress call, and the fifteen sperm whales that soon formed the group appeared "vigilant with their heads raised from the water facing different directions, and some of them were slapping the water with their tails" (p. 501). The killer whales began attacking, causing severe injuries. But, the researchers spotted additional groups of sperm whales as far as seven kilometers away traveling rapidly to join the group. When more sperm whales joined the group, they formed different shapes: a "raft-like" shape when twenty in number, a "spindle" shape when thirty in number, and when the sperm whale group was fifty strong, the killer whales ceased attacks and shortly thereafter were kilometers away (p. 502).

To confirm that an agent is aware of her action's costs and benefits, we may look to general considerations, such as the known cognitive, emotional, and social intelligences of the species, along with more specific considerations local to the setting of an action.

Both sperm whale behaviors-leaving the protective rosette and joining the group under attack-are moral acts with assurance. Sperm whales being a highly intelligent species of Cetacea with exceptional echolocation and sensory acuity, researchers believe that 
sperm whales can discern predatory intent before killer whales attack (Whitehead 2003). They can feel, see, and possibly smell themselves bleeding and spilling body oil into the water. Given that they continually echolocate to create three-dimensional images of their environment, including the killer whales as well as their own lost blood and body oil, and given that they had four hours to echolocate, see, and passively listen while the killer whales attacked, there is no basis for reasonable doubt that these sperm whales knew with certainty that killer whales were attacking them.

An attack by killer whales is worse when a sperm whale is outside the rosette than when she is inside its protection, and the attacks are more frequent. The fact that the sperm whales formed the rosette, sought its protection, and left it only when doing so helped them to return a sperm whale back into its protection shows that they know that being in the rosette is preferable and that leaving it will likely cause killer whales to attack them severely. A sperm whale therefore knows that an attack by killer whales is a significant cost. Likewise, a sperm whale knows that by leading a sperm whale back into the rosette, she benefits that sperm whale. In the first encounter, by leaving the protective rosette, a sperm whale knowingly brings great costs to herself and knowingly benefits another sperm whale. Their actions therefore satisfy the requirement that they are aware that their actions bring great costs to themselves and benefits to others. Their actions therefore satisfy the descriptive evidential criterion for moral agency. Conclusively, it is shown that sperm whales are moral agents.

The second encounter further corroborates this conclusion, since the behavior is similar at the group level and involves groups that are between one and seven kilometers away joining the group that killer whales are attacking. In humans, this would be like one group choosing to join and assist another group that headhunters are attacking with predatory intent when they could have easily fled. If a human group acted in this manner, we would arguably not hesitate to declare that it is a moral act with assurance. 
One might object that none of the actions shows moral agency with assurance because natural (gene, kin, or group) selection may explain the behavior of the sperm whales.

This is not an objection to my argument because my argument concerns proximate causes-moral motivations. And the objection concerns ultimate causes - the reasons behavior evolved. That clarification shows that this objection based on ultimate causes does not challenge my claim that sperm whales are motivated to promote the significant interests of other sperm whales, since my claim concerns proximate causes not ultimate causes. ${ }^{10}$

One may object that none of the actions shows moral agency because, in each instance, the sperm whale performing the action might be an immediate family member of the individual or individuals that she benefits. Due to the extensive degree to which one is emotionally invested in family, such an action is a selfinterested action, in which case, it is not a moral action.

Since sperm whale mothers birth a single calf every few years (Whitehead 2003), in order for the fifty group members in the second encounter to be immediate family, a mother would need to bear young with a zero mortality rate for hundreds of years. Since a female is fertile for a few decades, the fifty group members are not immediate family, and the objection is rebutted. Moreover, "sperm whale groups are not themselves particularly stable, often consisting of two or more largely matrilineal units that swim together for periods of days... [and] These social units may themselves split or merge" (Rendell and Whitehead, 2001, p. 315). Therefore, although in some cases, the sperm whale performing the action might be a family member, it is not possible that this is always the case. Moreover, if a family member or a friend might have performed some of the moral acts with assurance, this is not the basis of an insurmountable objection even against these, since it depends on the disputable claim that filial bonds cannot be the source of moral reasons. Robert Nozick (1981) and Christina Hoff Sommers (1986) 
argue compellingly that filial bonds can be the source of strong moral reasons. Nevertheless, it is important to point out that the relative cost of an action may outweigh considerations of filial bonds. An action for a family member with a low cost to self will usually be a weak example of moral agency, while an action with a high cost to self may be a strong example. For instance, placing oneself between a family member and an attacking predator or joining a group under predatory attack is a strong example. Since the sperm whales' actions are the stronger type, sperm whales perform moral acts with assurance and are therefore moral agents.

Rhesus monkeys: The experimenters tested rhesus monkeys in pairs with one monkey as the operator and another monkey as the stimulus animal. Two adjacent chambers are the operator's box and the stimulus animal's box. The operator's box contains two chains that deliver food when pulled, one delivering a tiny amount (enough that pulling the chain is, although worthwhile, not enough to reduce their growing hunger), the other delivering a large amount. The stimulus animal box's floor is an electric grid that delivers high frequency electroshocks through a monkey's feet. A one-way visual barrier divides the operator's box from the stimulus animal box, and it allows a monkey in the operator box to see inside the stimulus animal box, but not vice versa.

After training, all the monkeys could work the apparatus well. Researchers began the experiment 22 hours after withholding all food. If the monkey in the operator box pulled the chain delivering a tiny amount of food, she received it. If she pulled the chain delivering the large amount of food, she received the food, and the monkey in the stimulus animal box received a high frequency electroshock through her feet.

When the other side of the box was vacant, all monkeys operated the apparatus without hesitation. Once a monkey was in the stimulus animal box, however, they were reluctant to pull the chains. Some refrained entirely. This is an instance of moral agency in other 
species mitigating the suffering that results from unethical animal experimentation.

I will refer to monkeys in the operator box as "naïve" if they had never been shocked in the stimulus animal box, and "experienced" if they had been shocked. The study found that naive monkeys went with tiny amounts of food for 1.2 days, on average, while experienced monkeys went with tiny amounts of food for 7.6 days, on average, a difference that is statistically significant $(\mathrm{p}<0.01)$. One experienced monkey endured complete hunger for five days refraining from pulling any chains. Another endured complete hunger for twelve days (Masserman, 1964, p. 584). The studies clearly show several things. A majority of rhesus monkeys (25 of 33) prefer to bring great costs to themselves prolonging their extreme hunger-in order to promote other monkeys' significant interests by giving them a refuge from further torture. ${ }^{11}$ In addition, experiencing a shock had a significant effect.

Showing that the rhesus monkeys were aware of the costs to self and benefits to others is straightforward. It is beyond dispute that rhesus monkeys understand the relation of hunger to eating-one of the most basic items of knowledge for a rhesus monkey. We can be certain that they are aware of the costs to self, since they are fully trained on the apparatus and were tested to ensure that they understood the reward pairings of the chains to amounts of delivered food. The fact that naive monkeys had no food for 22 hours and chose, nevertheless, to endure even greater hunger for more than another day in order to avoid shocking the adjacent monkey shows that even though they had not experienced shock, they were sensitive to the behavior of the adjacent monkey, who would show dramatically increased bodily activity, thrashing of limbs, frantic jumping, and grimacing and vocalizations, all which occurs immediately after pulling the chain for the large amount of food. There is no reasonable basis for doubt therefore that when the stimulus animal monkey is present, the operator is aware that pulling the chain that administers a large amount of food results in two 
things-receiving a large amount of food and the adjacent monkey receiving pain. The monkeys are aware, therefore, of the costs and benefits.

Experienced monkeys know with certainty, of course, that the consequence for the adjacent monkey is the pain and distress that results from a shock. Naïve monkeys and especially experienced monkeys are therefore aware of the costs to self and benefits to others of the courses of action available to them, and their actions therefore satisfy the descriptive evidential criterion. The rhesus monkeys perform moral acts with assurance, and therefore, rhesus monkeys are moral agents.

Monkeys were housed three to a cage for one year before the experiment, and if a monkey in the operator box was the cagemate of the monkey in the stimulus animal box, he was willing to suffer worse hunger to avoid harming the monkey in the stimulus animal box with whom he lived than to avoid harming a strange monkey. Although this effect was not statistically significant $(p=0.07)$, it approached statistical significance. These findings are consistent with a human preference for persons with whom we share a filial bond, and assuming that our having these slight preferences does not challenge the foundation of moral agency in humans, then it also should not challenge it in rhesus monkeys.

An objection is that the study does not rule out the possibility that the monkeys were motivated out of a fear of retaliation, and if they were so motivated, then their behavior is not moral. If fear of retaliation were the motive, however, we would expect to see an increase in behavioral indications of things associated with such fear, such as dominance. Researchers showed with additional experiments, however, that there was no effect of dominance on the observed behaviors. Moreover, a stranger is equally or more likely to retaliate. Being a former cagemate of the operator monkey, however, protected a monkey some. Most importantly, being hungry for days is a long time to be hungry, even for a human, and the urgency of the present is strong during times of prolonged discomfort. It is simply 
implausible therefore that a monkey, or a human for that matter, might be motivated so strongly by thoughts of future possible scenarios while in the present grip of unrelenting discomfort.

\section{General Objections}

The two examples are proof that nonhuman mammals satisfy the evidential criterion for moral agency, which I defend as being sufficient for moral agency. I am likely to receive a certain type of counterargument that defends the view that, regardless of the examples of animal behavior, only humans are moral agents.

An objection is that the sperm whales and rhesus monkeys' actions are, although compassionate, caring, and kind actions, not motivated by a categorical imperative. The agent must assign herself a categorical or unconditional imperative based on duty-what it is right to do as determined by practical reason and apart from inclination. For it to be moral agency, the action must be motivated by a concern for the welfare of the other qua other-a source of concern (or in terms of the present discussion, a "source of significance"). There is not sufficient evidence that the sperm whales or rhesus monkeys are motivated by anything beyond compassion, care, and kindness.

In rebutting this sort of objection, it is first important to ask, perhaps if only rhetorically, If the evidence I provided is not sufficient to show that rhesus monkeys and sperm whales are motivated from duty or something similar, then what sort of evidence would? Although Kant's moral theory defines duty, his theory is generally understood to lack an account for how to confirm empirically when actions are performed from duty. In other words, stated in terms familiar to the present discussion, Kant's theory is taken to provide constitutive criteria of duty but no evidential criteria. Kant even warns that it would be speculation to claim that an action was actually motivated from duty because the mind and motives are never fully knowable. 
Despite those considerations, Kant seems to provide evidential criteria for performing a moral action. These center around his notion of the imputation of an action, which is a vital notion in Kant's The Metaphysics of Morals, ${ }^{12}$ and Kant states that "Imputation (imputatio) in the moral sense is the judgment by which someone is regarded as the author... of an action" (p. 19). Kant explains that "Subjectively, the degree to which an action can be imputed (imputabilitas) has to be assessed by the magnitude of the obstacles that had to be overcome" (ibid.). And, an example that Kant gives is "The greater the natural obstacles (of sensibility) and the less the moral obstacle (of duty), so much the more merit is to be accounted for a good deed, as when, for example, at considerable self-sacrifice I rescue a complete stranger from great distress" (ibid.). I suggest that imputation is a descriptive evidential criterion of duty in the sense that it concerns the actual conditions of attribution of moral worth to an action. Furthermore, by a principle of parity, the moral acts with assurance that the rhesus monkeys and sperm whales performed satisfy Kant's (descriptive evidential) criterion of imputabilitas. The rhesus monkeys have a very great natural obstacle in hunger. In addition, it would be very easy for them to pull the chain that delivers a large amount of food. The sperm whales in both encounters have great natural obstacles in the killer whales that are attacking them. In addition, it would be very easy for them to remain in the protective rosette in the first encounter and to flee the area in the second encounter. Consequently, when "assessed by the magnitude of the obstacles that had to be overcome," the rhesus monkeys and sperm whales may be regarded as the author of their good deeds. In a word, their actions may be said to be motivated by duty or something like duty.

One might object that the essence of morality resides in some capacity that, for one, only humans have, and for another, that sperm whales and rhesus monkeys do not exhibit. I will consider two possible forms of this objection, one based on Peter Singer's view and another based on Christine Korsgaard's view. 
One might object that the capacity to reason is advanced in humans over that of other animals to such a degree that it affords humans with capacities that all other animals lack and that such capacities are the basis for moral agency. Therefore, humans and no other animals are moral agents. Singer offers such an argument in his response to primatologist Frans de Waal's Tanner lectures. Singer writes,

In The Expanding Circle, I suggested that it is our developed capacity to reason that gives us the ability to take the impartial perspective. As reasoning beings, we can abstract from our own case and see that others, outside our group have interests similar to our own. We can also see that there is no impartial reason why their interests should not count as much as the interests of members of our own group, or indeed as much as our own interests. Does this mean that the idea of impartial morality is contrary to our evolved nature? Yes, if by "our evolved nature" we mean the nature that we share with the other social mammals from which we evolved. No nonhuman animals, not even the other great apes, come close to matching our capacity to reason. So if this capacity to reason does lie behind the impartial element of our morality, it is something new in evolutionary history (p. 145).

And later Singer states that "[perhaps] we can reject [our initial] emotional responses. . . only on the basis of other emotional responses, but the process involves reason and abstraction, and may lead us... to a morality that is more impartial than our evolutionary history as social mammals would-in the absence of that reasoning process-allow" (p. 150).

Developing Singer's line of thought into a complete objection, the idea is that an impartial morality depends on a humanlike capacity to reason. Since other social mammals, such as rhesus monkeys and sperm whales, have a much underdeveloped reasoning capacity when compared to humans, members of such species are incapable of abstracting from their own case and seeing that others outside their group (or individual situation, presumably) have similar 
interests to their own. Rhesus monkeys and sperm whales therefore cannot take an impartial perspective. Since according to Singer (1993, p. 12) the impartial perspective is the mark of the moral, social mammals such as rhesus monkeys or sperm whales are not moral agents.

Such an objection may be rebutted. The objection's first premise is that no nonhuman animals come close to matching our capacity to reason. Second, the capacity to reason lies behind the impartial element of our morality. Third, the impartial perspective is necessary to morality. From these claims, however, it would be a mistake to infer that only humans have any impartial element of morality. Singer's "impartial perspective" is most plausible when understood as a perspective that can have varying degrees of impartiality, since it must be a psychological capacity that will vary in its development between humans and within the same human over time. Sperm whales and rhesus monkeys adopt perspectives that are somewhere on a continuum of impartiality, so the question is whether the degree to which they have it is enough for moral agency. I believe the answer is "yes." In the second encounter with killer whales, sperm whales up to seven kilometers away swam to join the sperm whale group being attacked. In the first encounter of sperm whales and killer whales and in the rhesus monkey experiments, the moral agents adopted a perspective that was sufficiently impartial with regard to themselves in relation to one or more other animals such that they acted on the other's interests which they did despite their having a pressing self-interest or need. They knowingly underwent great hardship or costs to self in order to bring benefits, or avoid bringing harms, to the other. If these are not instances of "seeing that others outside [their] group have interests similar to [their] own," then neither Singer nor I must know what is. Even if we assume that humans are unmatched in their reasoning abilities, members of many species of mammal are, nevertheless, moral agents. 
One might object that in order to perform a moral action, one must be autonomous and freely choose to perform it; sperm whales and rhesus monkeys might not be entirely free to choose to perform any actions. Although animals, according to Kant, have sensation and choice (1996, p. 192), they always choose one inclination over other inclinations. ${ }^{13}$ Christine Korsgaard claims that "the capacity for normative self-government [/autonomy] requires...a certain form of self-consciousness: namely, consciousness of the grounds on which you propose to act as grounds" (p. 113). A nonhuman is conscious of the object that he fears or desires "as fearful or desirable, and so as something to be avoided or sought” (p. 113). Korsgaard claims, however, that "a rational animal is, in addition, conscious that she fears or desires the object, and that she is inclined to act in a certain way as a result" (p. 113). Her argument is that humans "do not merely haveintentions [but] assess and adopt them" (p. 113), and it is that sort of capacity that morality is centered on and that only humans have. Since "it is at this level that morality emerges" (p. 113) and since "the capacity for normative self-government... is probably unique to human beings...” (p. 116), it follows that humans and no animals have morality.

The first and most obvious, and perhaps the strongest, basis for rebutting Korsgaard's objection is in the fact that the primary basis for her distinction between animals and humans is higher-order thought. One's being "conscious that... [one has an emotional state or ground for action]" is higher-order thought. While being aware that it is always possible to build into a moral theory such complexity or high-level thought that virtually no one would actually satisfy its requirements, I point out that I have already suggested that higherorder thought is neither necessary nor sufficient for moral agency. Korsgaard claims that "it is at this level [being conscious of the ground of your beliefs] that morality emerges." She does not provide reason for believing, however, that morality emerges only at that point, as opposed to just developing to a higher-level. For another, although she prefaces her argument with claims to the contrary,${ }^{14}$ her 
argument does suffer from the common error of pretending to provide answers to open empirical questions. In addition to suggesting that the empirical evidence shows that higher-order thought, such as consciousness of the grounds of your beliefs, is unnecessary and insufficient for moral agency, I suggest that these capacities are psychological capacities had as a matter of degree, and as has been shown, nonhuman mammals have them in varying degrees.

Expecting a moral philosopher that is (confessedly) unacquainted with the empirical literature on animal behavior to decide whether any animals satisfy the criteria for moral agency is like expecting an aeronautical engineer to determine whether any animals are capable of flying a plane. The engineer may argue compellingly that only humans could fly a plane, but these arguments are beside the point if I produce animals that fly planes. Since I have produced animals that perform moral acts with assurance, the arguments of Kant, Singer, and Korsgaard that animals do not are beside the point. Regardless of the merits of their arguments in their own right, they are ineffective. I conclude that, despite their arguments to the contrary, moral agency exists in other species such as rhesus monkeys and sperm whales.

\section{Concluding Remarks}

The founder of cognitive ethology Donald Griffin points out that the touchstone of credibility for animal behavioral evidence is unprecedentedly unfair. In other areas of science, data are weighed and assessed reasonably. In animal behavioral studies, unusually strict criteria must be satisfied in order for the data to count as real evidence.

It is for this reason that I have argued the way I have, and I have succeeded in showing that members of both aquatic and land species of mammals satisfy the descriptive evidential criterion. Since the descriptive evidential criterion is stricter than the descriptive constitutive criterion, while the descriptive constitutive criterion is 
the more accurate criterion, it is likely that members of many species of mammals are moral agents, at least according to the framework I provided for moral agency. Moreover, the proofs and arguments that I have given of moral agency in nonhuman mammals casts a new look on how to interpret compelling examples of what are "candidate" actions according to my criteria. For instance, elephant researchers document numerous instances of elephants assisting injured or disabled elephants and rhinoceroses (Hart et al., 2008, p. 91). Though the costs to self may be small costs to self are not necessary for the constitutive criterion (they are only necessary evidentially), and it is highly likely that elephants would do these things even if the costs to self were greater. Finally, the same applies to hundreds of other instances of behavior in many other species of mammals. In conclusion, social mammals such as rhesus monkeys and sperm whales, and likely including the members of many other species, are moral agents.

\section{Notes}

1. Throughout his decades of psychiatric practice evaluating and treating 'many hundred psychopaths' (p. 188), Cleckley reports that he was never able to uncover "a sense of guilt or remorse (conscious or unconscious) in any of the psychopaths" that he studied (p. 131).

2. See Hare (2006) and Blair (1995) for review. Shaun Nichols (2002) reviews evidence to show that the capacity to make the moral/conventional distinction "indicates a basic capacity for moral judgment” (p. 222).

3. See Delfour and Marten (2001) for killer whale stage 4 mirror selfrecognition, see Hart et al. (2008) for review of elephants, dolphins, and primates.

4. Hauser and his colleagues dyed the hair on top of their head, which is a highly salient feature of their appearance. This produced selfdirected mirror behavior in them: "Only individuals with dyed hair and prior mirror exposure touched their head while looking in the mirror" (Hauser et al., 1995, p. 10811).

5. An animal may achieve a strong sense of psychological significance without any added complexity of thought. Positing an attunement to significance capacity in moral agents may, inversely, help to explain 
the existence of the psychopath since he lacks significance in himself (see Cleckley, 1976). Cleckley describes the psychopath's central deficit as an inability to experience life with the meaning and importance that define life for others (p. 371), which is similar to lacking an attunement to significance capacity.

6. In addition to including the condition "performs an action," this criterion also implicitly includes the condition of refraining from performing an action.

7. Since, as Cleckley explains, the pure psychopath's lack of personal significance prevents the psychopath from being able to acknowledge that others have significant interests, the psychopath cannot be motivated to act to support the significant interests of others, and thus fails the descriptive constitutive condition. Given the severe impairments that psychopaths show when it comes to what we deem moral behavior and moral attitudes, the psychopath's failure to satisfy this criterion is evidence that the descriptive constitutive criterion describes something that is possibly developmentally necessary for moral agency.

8. As with the previous criterion, this criterion also implicitly includes the condition of refraining from performing an action. The transition from the constitutive to the evidential criterion is a loss of precision because an agent is a moral agent by virtue of the nature and content of the agent's motives and beliefs (it is not necessary that an action bring a cost to self for it to be a moral action). Some opportunity cost to self may be implied in any action that supports others, since performing an action that supports others may prevent performing other actions that support oneself.

9. Satisfying it is possible without higher-order thought, as an agent may estimate costs to self and benefits to others with basic reasoning abilities and find significant interests in others with only higher-order intentionality. The more significant the costs to self, the better is the evidence of moral agency.

10. In any case, the objection to moral agency on the grounds of evolutionary pressure fares poorly in this case with sperm whales. The behavior of the sperm whales resulted in an exponentially greater number of casualties than would self-interested behavior. Thirty-five killer whales cannot consume more flesh in one feeding than that which is contained in one sperm whale. Were the sperm whales to behave according to a 'cold shoulder' policy, collectively seeking refuge in the rosette even when a fellow sperm whale was forced out by predators, then only a single sperm whale would have perished. In 
short, helping members who are pulled out of the rosette is not adaptive for the self or the species.

11. At least, rhesus monkeys as experimental subjects since some might have participated in more than one study

12. Although The Metaphysics of Morals is less popular, Kant wrote it later in his life and over a much longer time.

13. Kant was mistaken to make such claims about what are open empirical questions.

14. Christine Korsgaard writes, "although I believe the capacity for autonomy is characteristic of human beings and unique to human beings, the question how far in the animal kingdom that capacity extends is certainly an empirical one" (p. 112-113).

\section{References}

Baron-Cohen, S. 1995. Mindblindedness: An essay on autism and theory of mind. Cambridge: MIT Press.

Blair, R. 1995. A cognitive developmental approach to morality: Investigating the psychopath. Cognition 57:1-29.

Bourtchouladze, R. 2004. Memories are made of this: How memory works in humans and animals. Columbia University Press.

Cleckley, H. 1976. The mask of sanity: An attempt to clarify some issues about the so-called psychopathic personality, $5^{\text {th }}$ ed. Saint Louis: The C.V. Mosby Company.

DeGrazia, D. 1996. Taking animals seriously: Mental life and moral status. Cambridge: Cambridge University Press.

Delfour, F. and K. Marten. 2001. Mirror image processing in three marine mammal species: killer whales (Orcinus orca), false killer whales (Pseudorca crassidens) and California sea lions (Zalophus californianus). Behavioural Processes 53:181-90.

Hare, R. D. 1993. Without conscience: The disturbing world of the psychopaths among us. New York: Simon \& Schuster.

------ 1998. Psychopathy, affect and behavior. In D. J. Cooke, A. E. Forth, and R. D. Hare (eds.), Psychopathy: Theory, research and implications for society (pp. 105-37). Kluwer, Dordrecht.

------ 2006. Psychopathy: A clinical and forensic overview. Psychiatric Clinics of North America 29:709-24 
Hart, B., L. Hart, and N. Pinter-Wollman. 2008. Large brains and cognition: Where do elephants fit in? Neuroscience and Biobehavioral Reviews 32:86-98.

Hauser, M., J. Kralik, C. Botto-Mahan, M. Garrett, and J. Oser. 1995. Self-recognition in primates: phylogeny and the salience of species-typical traits. Proceedings of the National Academy of Sciences, 92:10811-4.

Hopkins, W., S. Wechkin, J. Masserman, and W. Terris Jr. 1964. Shock to a conspecific as an aversive stimulus. Psychonomic Science 1:47-8.

Goodall, J. 1986. The chimpanzees of Gombe: Patterns of behavior. Cambridge: Belknap Press of Harvard University Press.

Grant, C, J. Boucher, K. Riggs, and A. Grayson. 2005. Moral understanding in children with autism. Autism 9:317-31.

Griffin, D. 1992. Animal minds. Chicago: University of Chicago Press.

1998. From cognition to consciousness. Animal Cognition 1:3-16.

-_--_- 2001. Animals know more than we used to think. Proceedings of the National Academy of Science 98:4833-4.

Kant, I. 1996. The metaphysics of morals, M. J. Gregor (ed.). Cambridge: Cambridge University Press.

------ 1998. Groundwork of the metaphysics of morals, M. J. Gregor and C. M. Korsgaard (eds). Cambridge: Cambridge University Press.

Korsgaard, C. M. 2006. Morality in the distinctiveness of human action. In S. Macedo and J. Ober (eds.), Primates and philosophers: How morality evolved / Frans de Waal (pp. 98119). Princeton University Press.

Masserman, J., S. Wechkin, and W. Terris. 1964. "Altruistic" behavior in rhesus monkeys. American J ournal of Psychiatry 121:5845 .

McComb, K., D. Reby, L. Baker, C. Moss, and S. Sayailel. 2003. Long distance communication of acoustic cues to social identity in African elephants. Animal Behaviour 65:317-29.

Nichols, S. 2002. Norms with feeling: Towards a psychological account of moral judgment. Cognition 84:221-36. 
Nozick, R. 1981. Philosophical explanations. Harvard University Press.

Pryor, K. 2001. Cultural transmission of behavior in animals. Behavioral and Brain Sciences 24:352.

Rendell, L. and H. Whitehead. 2001. Culture in whales and dolphins. Behavioral and Brain Sciences 24:309-82.

Rogers, J., E. Viding, R. J. Blair, U. Frith, and F. Happe. 2008. Autism spectrum disorder and psychopathy: shared cognitive underpinnings or double hit? Psychological Medicine 36:1789 $-98$.

Singer, P. 1993. Practical ethics. Cambridge University Press.

--_--- 2006. Morality, reason, and the rights of animals. In S. Macedo and J. Ober (eds.), Primates and philosophers: How morality evolved / Frans de Waal (pp. 140-58). Princeton and Oxford University Press.

Smetana, J. 1993. Understanding of social rules. In M. Bennett, The development of social cognition: The child as psychologist (pp. 111-41). New York: Guilford Press.

Sommers, C. 1986. Filial morality. J ournal of Philosophy 83:439-56.

Vauclair, J., J. Fagot, and W. Hopkins. 1993. Rotation of mental images in baboons when the visual input is directed to the left cerebral hemisphere. Psychological Science 4:99-103.

Whitehead, H. 2003. Sperm whales: Social evolution in the oceans. Chicago and London: University of Chicago Press. 